\title{
A Case Study Evaluation Protocol to Assess Processes, Effectiveness and Impact of a Nurse Practitioner-Led Memory Clinic
}

\author{
Michael Bentley ${ }^{*}$, Melinda Minstrell11, Hazel Bucher², Martin Morrissey², \\ Andrew Robinson', Christine Stirling ${ }^{3}$ \\ ${ }^{1}$ Wicking Dementia Research and Education Centre, University of Tasmania, Hobart, Australia \\ ${ }^{2}$ Older Persons Mental Health Service, Department of Health and Human Services, Hobart, Australia \\ ${ }^{3}$ School of Health Sciences, University of Tasmania, Hobart, Australia \\ Email: " Michael.Bentley@utas.edu.au
}

Received 6 January 2014; revised 10 February 2014; accepted 19 February 2014

Copyright (C) 2014 by authors and Scientific Research Publishing Inc.

This work is licensed under the Creative Commons Attribution International License (CC BY). http://creativecommons.org/licenses/by/4.0/

(c) (i) Open Access

\section{Abstract}

The prevalence of dementia is predicted to increase significantly as the population ages and with no foreseeable cure options the burden of dementia will continue to grow. Early diagnosis provides many benefits, including timely access to appropriate support services and provision of tailored therapeutic interventions for people with dementia and their carers. Memory clinics are a key response to the need for specialist assessment and diagnosis of dementia. Multidisciplinary team memory clinics are considered the "gold standard"; however, such resource intensive clinics are likely unsustainable. The nurse-led memory clinic format may provide a primary care focused, diagnostic service for dementia that does not have the cost implications of multidisciplinary memory clinics but there is limited research using nurse practitioners. This study is exploring the potential of a nurse-led memory clinic as a primary health care approach to health promotion (brain health awareness), disease prevention (risk factor reduction) and early intervention (diagnosis and management of dementia). A realistic evaluation of a nurse practitioner-led memory clinic is described. Realistic evaluation is concerned not only with the outcomes of an intervention but also with the context and mechanisms of the intervention. We are using a mixed methods case study design to describe and evaluate the impact of the nurse practitioner-led memory clinic. The nurse practitioner in this study is an advanced practice aged care nurse who focuses on mental health, and dementia diagnosis, management and risk factor reduction. This study seeks to inform the development of an expanded scope role for nurse practitioners in assessment and referrals for dementia diagnosis. The heterogeneity of clients attending the nurse-led memory clinic will allow us to evaluate what works in the memory clinic, for whom, and under what circumstances, in what respects, and to what extent.

\footnotetext{
"Corresponding author.
} 


\section{Keywords}

\section{Realistic Evaluation; Dementia Diagnosis; Nurse Practitioner; Memory Clinic; Australia}

\section{Introduction}

In Australia, the prevalence of dementia is predicted to increase significantly as the population ages [1] [2]. Without preventative measures, the burden of dementia will continue to grow [3]. The potential demand on health services is enormous, given that 50 to 80 per cent of people with dementia are yet to receive a formal diagnosis [4]. The challenge for the health system is to develop cost-effective strategies for risk reduction and timely intervention [3]. Timely diagnosis of dementia is important as it enables people with dementia and their families to engage with appropriate support services, and receive tailored, therapeutic interventions [5]. A strong economic argument supports earlier diagnosis followed by timely interventions for people with dementia and their carers. A recent economic evaluation in the United Kingdom found significant cost savings and health benefits in early assessment for Alzheimer's disease (AD) and pharmacological treatment of those with AD [6]. Furthermore, there are many non-pharmacological (that is, psychological, psychosocial and psychoeducational) interventions that can improve the quality of life for people with dementia and their carers [4].

\subsection{Issues in Early Diagnosis of Dementia in Primary Health Care}

Primary health care is a comprehensive and cost-effective approach to health promotion, disease prevention and early intervention [7]. There are many factors relating to primary health care systems and primary health care providers that contribute to dementia diagnoses being missed or delayed in primary care [8]. The system factors include lack of resources (e.g., services and specialists) and financial constraints on primary health care providers (e.g., low financial reimbursement) [8]. Primary health care provider factors include knowledge gaps related to dementia care including the legal rights of patients [9], lack of confidence to diagnose [10], time to elicit a diagnosis [8], and nihilistic attitudes regarding the benefits of a diagnosis [11], all of which may contribute to diagnosis delays [9]. Specific barriers to dementia diagnosis by general practitioners (GPs), who in Australia are the key primary health care providers [12], include varied presentations and causes of dementia, the time consuming nature of dementia diagnosis and subsequent counselling and service referral, along with additional social constraints such as stigmatization, social isolation and a perception that support services are rarely available [11] [13] [14]. As a result, GPs miss up to 70 per cent of early dementia or cognitive decline cases, with diagnostic delays from symptom onset of up to three years [13] [15] [16]. These missed diagnoses are problematic because early diagnosis provides benefits, such as people with dementia being able to make plans for care and deal with financial and legal matters while they retain adequate cognitive capacity, and the provision of tailored therapeutic interventions to increase quality of life for people with dementia and their carers [17]. Further, some GPs believe dementia care should be in the specialist domain [18].

\subsection{The Role of Memory Clinics}

Memory clinics are seen as a key response to the need for specialist and timely assessment of dementia [19]. As a primary health care service, they have the potential to play an essential role in diagnosing dementia then supporting the person with dementia, and their carers [20] [21]. A memory clinic is "defined as an ambulatory assessment service dedicated solely to those with memory and related cognitive disorders" [22], pp. 696-697. Memory clinics have continuously remodeled themselves since they were first described in the 1980s, reflecting different settings with varying clients and diverse activities undertaken [23]. Memory clinics have been used in urban and rural settings and range in their post diagnostic involvement [20]. Typically, out-patient memory clinics are available one or two days per week and headed by a doctor [22] [23]. Multidisciplinary memory clinics are commonly used to provide an effective and specialised approach to dementia diagnosis and early support [24] [25]. The multidisciplinary team includes a core team of clinicians, and often features a senior nurse and nonclinical support staff [22] [23].

Woodward and Woodward [22] provided the first comprehensive description of Australian memory clinics, 
identifying twenty-three clinics, with most located in the state of Victoria, often staffed by neuropsychologists, geriatricians, and nurses. A clinic doctor typically undertook the initial assessment, with clients being seen, on average, three times (e.g., assessment, feedback, and follow-up) with assessment consultations generally lasting about four hours and feedback consultations taking about 45 minutes [22]. Multidisciplinary team memory clinics are considered the "gold standard"; however their financial viability has been questioned, with concerns that the resource intensive nature of such clinics is likely unsustainable [26]. With the burgeoning numbers of dementia cases, alternatives are needed [27].

The concept of a nurse-led memory clinic is seeding globally and may provide a primary care focused, diagnostic service for dementia that does not have the cost implications of multidisciplinary services [19] [28]. There is an important distinction between nurses screening for dementia in memory clinics, as opposed to diagnosing dementia. The majority of published studies detail nurses conducting a screening assessment, which is assessed by specialists who provide the final diagnosis for clients. For example, Gonçalves et al. [29] described research nurses providing home based assessments, the results of which were provided to experienced senior physicians who made a diagnosis following an examination and further tests as required. However, one United Kingdom study, which reported specialised nurses undertaking home based assessments, demonstrated that nurses can diagnosis dementia accurately (these nurses were found to detect dementia with 94 per cent accuracy and sub-diagnose dementia with 84 per cent accuracy when compared to multidisciplinary team diagnosis) [27].

Given the relatively limited and sometimes conflicting evidence, further research is needed on expanding the role of advanced practice nurses to expedite the diagnosis of dementia and facilitate access to care pathways. There is potential for aged care nurse practitioners to fill this role [30]. Nurse practitioner roles have existed in the US and Canada since the 1960s, the UK followed in the 1980s [31]. In Australia, the first nurse practitioners were endorsed in the state of New South Wales in 2000 [32]. The title of nurse practitioner can only be used by a person who has been endorsed by the Australian Health Practitioners Regulation Agency. As at June 2013, there were approximately 926 endorsed nurse practitioners in Australia [33]. Nurse practitioners are experts in specific areas of nursing and have completed both advanced university study at a Master's degree level and extensive clinical training to expand upon the traditional role of a Registered Nurse. These nurses use extended skills, knowledge and experience in the assessment, planning, implementation, diagnosis and evaluation of care required within in their specialised scope of practice.

A team of researchers and practitioners from the University of Tasmania and the Tasmanian Department of Health and Human Services is exploring the potential of a nurse-led memory clinic (NLMC) as a model of practice for nurse practitioners in aged care to address the rapidly rising demand for dementia specialist services and increase the numbers of Tasmanians receiving a timely dementia diagnosis. The nurse practitioner in this clinic is an advanced practice aged care nurse who focuses on mental health, and dementia diagnosis, management and risk factor reduction.

\section{Methods}

This paper describes the realistic evaluation design for the NLMC within a case study framework. Demographic and clinical data from clients, videorecording of consultations, clinic documentation, and interviews will be used to evaluate what works in the NLMC, for whom, and under what circumstances, in what respects, to what extent, and why [34]. Realistic evaluation is concerned not just with the outcomes of an intervention (in this case, a free assessment and management service for people with memory and cognitive changes) but also with the context and mechanisms of the intervention [35]-[37]. This is important because realistic evaluation "acknowledges that the outcomes of a project are confined to not only improved patient outcomes but also staff and organisational outcomes" [37], p. 235. In the context of this study this is important because not only does the nurse-led memory clinic seek to improve access to primary health services for older persons, particularly those with dementia, but it also seeks to demonstrate in what ways an aged care nurse practitioner can add value to specialist dementia services with the provision of cost-effective holistic primary care.

\subsection{Setting}

The study is being conducted in collaboration with the Older Persons Mental Health Service (OPMHS) of the Tasmanian Department of Health and Human Services. The OPMHS provides a free and confidential mental health service to assist people over 65 years of age who have a mental illness and/or impaired cognitive func- 
tioning with challenging behaviour. The nurse-led memory clinic operates from the OPMHS southern site one day per week.

\subsection{Model Design}

The nurse-led memory clinic aims to provide an assessment and management service for people with memory and cognitive changes. Clients either self-refer or are referred by health professionals for assessment. The clinic offers a two-visit model and retains a primary health care focus by ensuring that general practitioners remain well-informed. The assessment is conducted by the nurse practitioner and involves taking a comprehensive history from the client and, importantly, a corroborative history from a relative, friend or primary carer. This is followed by the development of a personalized plan for those with identified cognitive deficits, which is prepared by the nurse practitioner. The nurse-led memory clinic model encourages referrals from general practitioners and maintains close links with GPs and specialists while providing support in the time consuming aspects of assessment, diagnosis and referral, and providing an alternative avenue for individuals to access initial assessment (Figure 1).

This memory clinic model adapts key features of two other models-self-referral and health professional referral. Self-referral by community members is used by the community memory clinics developed by The Research Institute for the Care of the Elderly at St Martin's Hospital in Bath, UK [38]. Health professional referral is used by most other memory clinic services.

The NLMC assessment process results in one of four diagnoses for clients and these will be used as criteria for validation:

- Dementia-a probable Alzheimer's like dementia based on DSM IV-TR diagnostic criteria for the diagnosis of Alzheimer's disease [39]. While the nurse practitioner may identify clinical signifiers suggestive of a differential diagnosis, and may indicate this in the diagnosis, the purpose of the clinic is to identify whether the client has a dementia type illness and to refer appropriately.

- Mild cognitive impairment/possible dementia when a patient has subtle but definite cognitive deficits as demonstrated on cognitive screening tests and/or history but these are not of a degree that warrant a diagnosis of dementia.

- A picture not typical of a dementing illness but where significant physical or psychiatric disability is identified warranting further specialist assessment, e.g. severe depressive illness.

- No dementia.

\subsection{Study Design}

We are using a mixed methods case study design to describe and evaluate the impact of the nurse practitioner led memory clinic [40]. Case study methods are widely used in health and social care research and are increa-

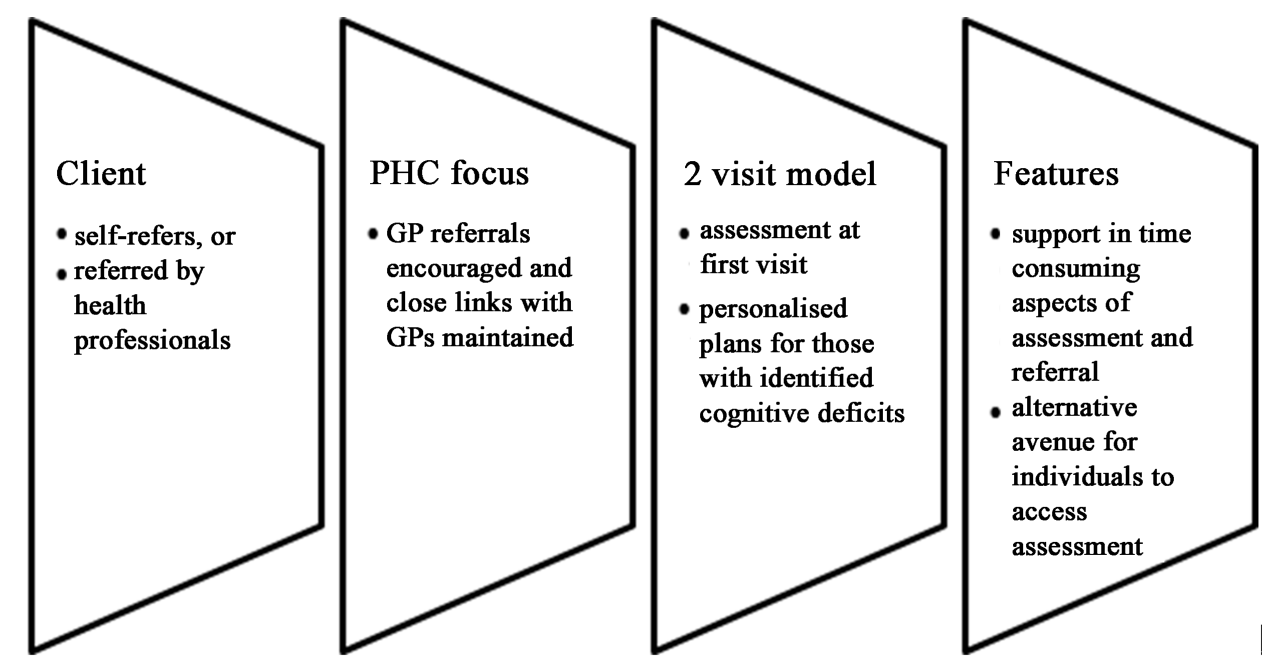

Figure 1. The nurse-led memory clinic model. 
singly popular in nursing research [41]. Case studies are empirical enquiries that investigate a "contemporary phenomenon in depth and within its real-life context, especially when the boundaries between phenomenon and context are not clearly evident" [42], p. 18. In health services research, there are several levels of context-the policy level, theoretical and professional levels, and the local organizational level. Bergen and While [43] illustrate this in describing their case study of case management in community nursing, in particular the interrelationship between case management and the provision of community nursing services in their case study site. In our study, the case-a nurse-led memory clinic — can be built up through subunits of analysis (e.g., nurse practitioner practices) within the different levels of context. Figure 2 (adapted from Bergen and While [43]) depicts this interrelationship in our study.

\subsection{Study Population}

All clients who self-refer or are referred to the nurse-led memory clinic are invited to participate in the study. After registering for an appointment, participants are provided with information about the clinic and research project. Attendance at the clinic is taken as consent to have assessments undertaken in the new service model.

\subsection{Data Collection and Analysis}

The data for this study will be used to evaluate both the process and outcomes of assessing and diagnosing dementia and other cognitive decline in the memory clinic. Furthermore, the study is concerned with what features of nurse practitioner-client interaction in memory clinics can be used in teaching and coaching of nurse practitioners [44] [45]. Table 1 details the research questions and data collection methods for the evaluation.

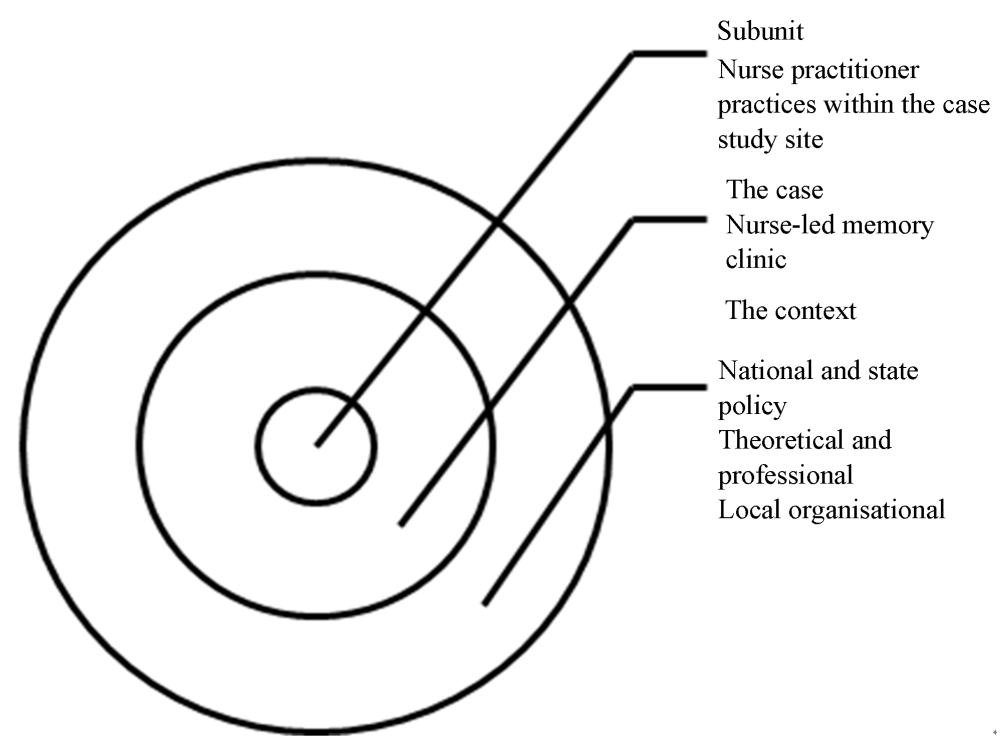

Figure 2. The case and context.

Table 1. Research questions and data collection methods.

\begin{tabular}{ll}
\hline Research question & Data collection methods \\
$\begin{array}{l}\text { Does a nurse-led memory clinic facilitate dementia diagnosis for clients, and for general } \\
\text { practitioners? }\end{array}$ & $\begin{array}{l}\text { Client data } \\
\text { Documentation } \\
\text { Interviews }\end{array}$ \\
$\begin{array}{l}\text { What is the diagnostic consistency between nurse practitioner, an old age psychiatrist/geriatrician } \\
\text { and general practitioner? Are a nurse practitioner's cognitive impairment diagnoses consistent with Documentation } \\
\text { those of an old age psychiatrist/geriatrician? }\end{array}$ & Videorecordings \\
$\begin{array}{l}\text { What are the client teaching and coaching components of nurse practitioner interventions in } \\
\text { consultation with clients presenting to investigate possible cognitive impairment? }\end{array}$ & Videorecordings \\
\hline
\end{tabular}




\subsection{Client Data and Documentation}

SPSS Version 20 is used to collate data about participants' cognitive capacity (using the Addenbrooke's-R Aus version) and likelihood of dementia (combination of screening tools Addenbrooke's and IQCODE), as well as executive function tests such as Frontal Assessment Battery and Trail Making tests where appropriate, and any impact on their quality of life (Quality of Life-AD). Other demographic and clinical details of the client (e.g., family history, supporter's report, geriatric depression scale score, social history-schooling, occupation, relationship status, and smoking) are also being collected. Descriptive statistical analysis will be used for the dementia assessments, and where relevant will be compared to published reference data.

\subsection{Videorecording}

Direct observation of videorecorded interviews or video consultations has been shown to be a useful diagnostic tool for dementia [46]. Further, reviews of videorecorded consultations have proved valuable in other areas of medical research [47]-[49]. The method of attaining data to describe the client teaching and coaching components of nurse practitioner interventions within the NLMC is supported within the literature [50]-[52]. Specifically, video-recorded consultations have been effective in describing consultation communication quantitatively and generating qualitative descriptions of medical communication, allowing ongoing development of the clinician consultation [47] [48] [53]. The use of direct observation provides an effective means to identify health practitioner communication practices that need to be changed and that improve patient outcomes. Furthermore, digital video observation increases the richness of the data available to researchers [54].

Videorecording consultations in the nurse-led memory clinic will allow the researchers to i) qualitatively describe the client teaching and coaching components of nurse practitioner interventions within the NLMC; and ii) assess the capacity of the nurse practitioner to diagnose through checking the inter-rater agreement between the nurse practitioner diagnosis and an old age psychiatrist/geriatrician and a general practitioner, who reviews the video and assessment documentation.

\subsection{Interviews}

Semi-structured interviews using an interview guide are being conducted with the nurse practitioner at regular points throughout the study. Interviews are being taped and transcribed. The interview questions explore the nurse practitioner role (e.g., changes or issues in logistical arrangements, facilitating and constraining factors to undertaking the role), communication (i.e., interactions with colleagues and others) and reflections on working with clients (including typical and extreme cases). NVivo (version 10) will be used to manage and analyze data from the interviews.

As this evaluation seeks to inform policy and practice, qualitative framework analysis will be used to analyze the interview data [55]. This is a five-step process that involves 1) Familiarization with the raw data; 2) Identifying a thematic framework; 3) Indexing the thematic framework systematically to the data; 4) Charting the data according to the appropriate part of the thematic framework to which they relate; and 5) Mapping and interpretation of the charts with a view to providing explanations for the findings [56].

\subsection{Ethical Considerations}

The consent is a layered consent with four points. At the first visit, participants are asked to consent to their medical information being used to evaluate the project outcomes. Participants are reassured that refusal will not affect their ability to receive free assessments. Information about this consent is also provided with the pre-attendance information. Consent is also sought from participants for their consultations to be videorecorded. This consent is separate to the consent to use their information, and the assessment goes ahead irrespective of whether it is videorecorded or not. Participants who consent to videorecording are informed that an old age psychiatrist/geriatrician and a general practitioner will be reviewing the videorecording and their test results (those held within the nurse-led memory clinic and attained by the nurse practitioner in normal practice) to make their own individual diagnostic assessments. Additionally, participants are informed that researchers will review their videorecordings to describe the consultation practices of the nurse practitioner. Participants may find the presence of the video recorder and/or the idea of being recorded unsettling. As participants may be uncomfortable and/or anxious about being videorecorded, they can revoke consent at any time. Furthermore, the nurse prac- 
titioner will suggest this if participants appear anxious or uncomfortable. Finally, participants are asked if they consent to being contacted by the researchers in the future in regard to other possible research. This study has received ethical approval from the Tasmania Health and Medical Human Research Ethics Committee.

\section{Discussion}

Nurse-led memory clinics have the potential to improve dementia care [19] but there is limited research with nurse practitioners. This study seeks to inform the development of an expanded scope role for nurse practitioners in assessment and referrals for dementia diagnosis. Clients self-refer or are referred by health professionals to the memory clinic and their assessment process results in a diagnosis of dementia, mild cognitive impairment, another physical or psychiatric disability, or no cognitive decline. The heterogeneity of these clients will allow us to evaluate what works in the NLMC, for whom, and under what circumstances, in what respects, and to what extent. Although, the findings from small-scale research may not have empirical generalizability, they can provide "theoretical explanations of phenomena" [57], p. 788. A benefit of using a realistic evaluation approach is that explanation, which is based on theory and methods, can provide analytic or theoretical generalizability to similar contexts [42]. The dissemination of research findings will inform service development and practice in cognitive impairment assessment, dementia diagnosis, nurse practitioner roles, and memory clinics.

\section{Acknowledgements}

This study is a part of the Nurse Practitioner IM/NPACT Tasmania Project (Evaluating Aged Care Nurse Practitioners Models). This is an Australian Government initiative. The study has ethical approval from the Tasmania Health and Medical Human Research Ethics Committee. An earlier version of this paper was presented at the 2013 Primary Health Care Research Conference held 10 - 12 July in Sydney Australia. Abstract at http://www.phcris.org.au/conference/browse.php?id=7562

\section{References}

[1] Jorm, A.F., Dear, K.B. and Burgess, N.M. (2005) Projections of Future Numbers of Dementia Cases in Australia with and without Prevention. Australian and New Zealand Journal of Psychiatry, 39, 959-963. http://dx.doi.org/10.1080/j.1440-1614.2005.01713.x

[2] Access Economics (2009) Keeping Dementia Front of Mind: Incidence and Prevalence 2009-2050. http://www.fightdementia.org.au/common/files/NAT/20090800 Nat AE FullKeepDemFrontMind.pdf

[3] Nepal, B., Ranmuthugala, G., Brown, L. and Budge, M. (2008) Modelling Costs of Dementia in Australia: Evidence, Gaps, and Needs. Australian Health Review, 32, 479-487. http://dx.doi.org/10.1071/AH080479

[4] Prince, M.J., Bryce, D.R. and Ferri, C.P. (2011) The Benefits of Early Diagnosis and Intervention. http://www.alz.co.uk/research/WorldAlzheimerReport2011.pdf

[5] Burns, A. and Iliffe, S. (2009) Alzheimer’s Disease. British Medical Journal, 338, b158. http://dx.doi.org/10.1136/bmj.b158

[6] Getsios, D. (2012) An Economic Evaluation of Early Assessment for Alzheimer's Disease in the United Kingdom. Alzheimer's \& Dementia, 8, 22-30. http://dx.doi.org/10.1016/j.jalz.2010.07.001

[7] Labonté, R., Pooyak, S., Baum, F., Schaay, N., Packer, C., Laplante, D., et al. (2008) Implementation, Effectiveness and Political Context of Comprehensive Primary Health Care: Preliminary Findings of a Global Literature Review. Australian Journal of Primary Health, 14, 58-67. http://dx.doi.org/10.1071/PY08037

[8] Bradford, A., Kunik, M., Schulz, P., Williams, S. and Singh, H. (2009) Missed and Delayed Diagnosis of Dementia in Primary Care: Prevalence and Contributing Factors. Alzheimer Disease \& Associated Disorders, 23, 306-314. http://dx.doi.org/10.1097/WAD.0b013e3181a6bebc

[9] Hansen, E., Robinson, A., Mudge, P. and Crack, G. (2005) Barriers to the Provision of Care for People with Dementia and Their Carers in a Rural Community. Australian Journal of Primary Health, 11, 72-79. http://dx.doi.org/10.1071/PY05010

[10] Mitchell, A.J., Meader, N. and Pentzek, M. (2011) Clinical Recognition of Dementia and Cognitive Impairment in Primary Care: A Meta-Analysis of Physician Accuracy. Acta Psychiatrica Scandinavica, 124, 165-183. http://dx.doi.org/10.1111/j.1600-0447.2011.01730.x

[11] Hansen, E.C., Hughes, C., Routley, G. and Robinson, A.L. (2008) General Practitioners’ Experiences and Understand- 
ings of Diagnosing Dementia: Factors Impacting on Early Diagnosis. Social Science \& Medicine, 67, 1776-1783. http://dx.doi.org/10.1016/j.socscimed.2008.09.020

[12] Wiese, M., Jolley, G., Baum, F., Freeman, T. and Kidd, M. (2011) Australia’s Systems of Primary Healthcare-The Need for Improved Coordination and Implications for Medicare Locals. Australian Family Physician, 40, 995-999. http://search.informit.com.au/documentSummary;dn=686937046799945;res=IELHEA

[13] Bond, J., Stave, C., Sganga, A., O’Connell, B. and Stanley, R.L. (2005) Inequalities in Dementia Care across Europe: Key Findings of the Facing Dementia Survey. International Journal of Clinical Practice, Supp. 59, 8-14. http://dx.doi.org/10.1016/j.socscimed.2008.09.020

[14] Greenway-Crombie, A., Snow, P., Disler, P., Davis, S. and Pond, D. (2012) Influence of Rurality on Diagnosing Dementia in Australian General Practice. Australian Journal of Primary Health, 18, 178-184. http://dx.doi.org/10.1071/PY12008

[15] Ganguli, M., Rodriguez, E., Muslant, B., Richards, S., Pandav, R., Vander Bilt, J., et al. (2004) Detection and Management of Cognitive Impairment in Primary Care: The Steel Valley Seniors Survey. Journal of the American Geriatrics Society, 52, 1668-1675. http://dx.doi.org/10.1111/j.1532-5415.2004.52459.x

[16] Valcour, V.G., Masaki, K.H., Curb, J.D. and Blanchette, P.L. (2000) The Detection of Dementia in the Primary Care Setting. Archives of Internal Medicine, 160, 2964-2968. http://dx.doi.org/10.1001/archinte.160.19.2964

[17] Brodaty, H. (2007) Early Diagnosis of Dementia. http://www.fightdementia.org.au/common/files/NAT/20070300_Nat_NP_10EarlyDiagnDem.pdf

[18] Turner, S., Iliffe, S., Downs, M., Wilcock, J., Bryans, M., Levin, E., Keady, J. and O’Carroll, R. (2004) General Practitioners' Knowledge, Confidence and Attitudes in the Diagnosis and Management of Dementia. Age and Ageing, 33, 461-467. http://dx.doi.org/10.1093/ageing/afh140

[19] Christian, D. (2009) Nurse-Led Memory Clinics Set to Improve Dementia Care in England. Nursing Older People, 21, 5.

[20] Szymczynska, P., Innes, A., Mason, A. and Stark, C. (2011) A Review of Diagnostic Process and Postdiagnostic Support for People with Dementia in Rural Areas. Journal of Primary Care \& Community Health, 2, 262-276. http://dx.doi.org/10.1177/2150131911404705

[21] Lee, L., Hillier, L., Stolee, P., Heckman, G., Gagnon, M., McAiney. C. and Harvey, D. (2010) Enhancing Dementia Care: A Primary Care-Based Memory Clinic. Journal of the American Geriatrics Society, 58, 2197-2204. http://dx.doi.org/10.1111/j.1532-5415.2010.03130.x

[22] Woodward, M.C. and Woodward, E. (2009) A National Survey of Memory Clinics in Australia. International Psychogeriatrics, 21, 696-702. http://dx.doi.org/10.1017/S1041610209009156

[23] Jolley, D., Benbow, S.M. and Grizzell, M. (2006) Memory Clinics. Postgraduate Medical Journal, 82, 199-206. http://dx.doi.org/10.1136/pgmj.2005.040592

[24] Phipps, A.J. and O’Brien, J.T. (2002) Memory Clinics and Clinical Governance-A UK Perspective. International Journal of Geriatric Psychiatry, 17, 1128-1132. http://dx.doi.org/10.1002/gps.761

[25] Wolfs, C.A.G., Dirksen, C.D., Severens, J.L. and Verhey, F.R.J. (2006) The Added Value of a Multidisciplinary Approach in Diagnosing Dementia: A Review. International Journal of Geriatric Psychiatry, 21, 223-232. http://dx.doi.org/10.1002/gps.1454

[26] Gladman, J.R.F., Jones, R.G., Radford, K., Walker, E. and Rothera, I. (2007) Person-Centred Dementia Services Are Feasible, but Can They Be Sustained? Age and Ageing, 36, 171-176. http://dx.doi.org/10.1093/ageing/afl161

[27] Page, S., Hope, K., Bee, P. and Burns, A. (2008) Nurses Making a Diagnosis of Dementia-A Potential Change in Practice? International Journal of Geriatric Psychiatry, 23, 27-33. http://dx.doi.org/10.1002/gps.1831

[28] Hain, D., Dunn, D. and Tappen, R. (2011) Patient-Provider Partnership in a Memory Disorder Center. Journal of the American Academy of Nurse Practitioners, 23, 351-356. http://dx.doi.org/10.1111/j.1745-7599.2011.00619.x

[29] Gonçalves, D., Arnold, E., Appadurai, K. and Byrne, G.J. (2011) Case Finding in Dementia: Comparative Utility of Three Brief Instruments in the Memory Clinic Setting. International Psychogeriatrics, 23, 788-796.

[30] Arbon, P., Bail, K., Eggert, M., Gardner, A., Hogan, S., Phillips, C., et al. (2009) Reporting a Research Project on the Potential of Aged Care Nurse Practitioners in the Australian Capital Territory. Journal of Clinical Nursing, 18, 255-262. http://dx.doi.org/10.1111/j.1365-2702.2008.02452.x

[31] Driscoll, A., Worrall-Carter, L., O’Reilly, J. and Stewart, S, (2005) A Historical Review of the Nurse Practitioner Role in Australia. Clinical Excellence for Nurse Practitioners, 9, 141-152.

[32] Australian College of Nurse Practitioners (2014) History. http://acnp.org.au/history

[33] Nursing and Midwifery Board of Australia (2013) Statistics. http://www.nursingmidwiferyboard.gov.au/About/Statistics.aspx

[34] Wong, G., Greenhalgh, T., Westhorp, G. and Pawson, R. (2012) Realist Methods in Medical Education Research: 
What Are They and What Can They Contribute? Medical Education, 46, 89-96. http://dx.doi.org/10.1111/j.1365-2923.2011.04045.x

[35] Douglas, F.C., Gray, D.A. and van Teijlingen, E.R. (2010) Using a Realist Approach to Evaluate Smoking Cessation Interventions Targeting Pregnant Women and Young People. BMC Health Services Research, 10, 49. http://dx.doi.org/10.1186/1472-6963-10-49

[36] Pawson, R. and Tilley, N. (1997) Realistic Evaluation. Sage Publications, London.

[37] Wand, T., White, K. and Patching, J. (2010) Applying a Realist(ic) Framework to the Evaluation of a New Model of Emergency Department Based Mental Health Nursing Practice. Nursing Inquiry, 17, 231-239. http://dx.doi.org/10.1111/j.1440-1800.2010.00488.x

[38] The Research Institute for the Care of the Elderly (2011-2014) Memory Clinic. http://www.rice.org.uk/memory+clinic

[39] McKeith, I., Glasako, D., Kosaka, K., Perry, E., Dickson, D., Hansen, L., et al. (1996) Consensus Guidelines for the Clinical and Pathologic Diagnosis of Dementia with Lewy Bodies (DLB): Report of the Consortium on DLB International Workshop. Neurology, 47, 113-124. http://dx.doi.org/10.1212/WNL.47.5.1113

[40] Gardner, G., Carryer, J., Dunn, S. and Gardner, A. (2004) The Nurse Practitioner Standards Project. Australian Nursing and Midwifery Council, Canberra.

[41] Anthony, S. and Jack, S. (2009) Qualitative Case Study Methodology in Nursing Research: An Integrative Review. Journal of Advanced Nursing, 65, 1171-1181. http://dx.doi.org/10.1111/j.1365-2648.2009.04998.x

[42] Yin, R.K. (2008) Case Study Research: Design and Methods. 4th Edition, Sage Publications, Thousand Oaks.

[43] Bergen, A. and While, A. (2000) A Case for Case Studies: Exploring the Use of Case Study Design in Community Nursing Research. Journal of Advanced Nursing, 31, 926-934. http://dx.doi.org/10.1046/j.1365-2648.2000.01356.x

[44] Caris-Verhallen, W.M.C.M., Kerkstra, A., Bensing, J.M. and Grypdonck, M.H.F. (2000) Effects of Video Interaction Analysis Training on Nurse-Patient Communication in the Care of the Elderly. Patient Education and Counseling, 39, 91-103. http://dx.doi.org/10.1016/S0738-3991(99)00094-4

[45] Cameron, N. and McMillan, R, (2006) Enhancing Communication Skills by Peer Review of Consultation Videos. Education for Primary Care, 17, 40-48.

[46] Martin-Khan M., Varghese, P., Wootton, R. and Gray, L. (2008) Physical Examination and Diagnosis of Dementia for Video Consultation. Journal of the American Geriatrics Society, 56, 947-949. http://dx.doi.org/10.1111/j.1532-5415.2008.01658.x

[47] Fine, E., Reid, M.C., Shengelia, R. and Adelman, R.D. (2010) Directly Observed Patient-Physician Discussions in Palliative and End-of-Life Care: A Systematic Review of the Literature. Journal of Palliative Medicine, 13, 595-603. http://dx.doi.org/10.1089/jpm.2009.0388

[48] Roter, D. and Larson, S. (2002) The Roter Interaction Analysis System (RIAS): Utility and Flexibility for Analysis of Medical Interactions. Patient Education and Counseling, 46, 243-251. http://dx.doi.org/10.1016/S0738-3991(02)00012-5

[49] Salih, S.A., Wootton, R., Beller, E. and Gray, L. (2007) The Validity of Video Clips in the Diagnosis of Gait Disorder. Journal of Telemedicine and Telecare, 13, 333-336. http://dx.doi.org/10.1258/135763307782215406

[50] Gilbert, D.A. and Hayes, E. (2009) Communication and Outcomes of Visits between Older Patients and Nurse Practitioners. Nursing Research, 58, 283-293. http://dx.doi.org/10.1097/NNR.0b013e3181ac1413

[51] Hayes, E. (2006) Promoting Nurse Practitioner Practice through Research: Opportunities, Challenges, and Lessons. Journal of the American Academy of Nurse Practitioners, 18, 180-186. http://dx.doi.org/10.1111/j.1745-7599.2006.00118.x

[52] Riley, R.G. and Manias, E. (2004) The Uses of Photography in Clinical Nursing Practice and Research: A Literature Review. Journal of Advanced Nursing, 48, 397-405. http://dx.doi.org/10.1111/j.1365-2648.2004.03208.x

[53] Coleman, T. (2000) Using Video-Recorded Consultations for Research in Primary Care: Advantages and Limitations. Family Practice, 17, 422-427. http://dx.doi.org/10.1093/fampra/17.5.422

[54] Pearce, C., Arnold, M., Phillips, C. and Dwan, K. (2010) Methodological Considerations of Digital Video Observation: beyond Conversation Analysis. International Journal of Multiple Research Approaches, 4, 90-99. http://dx.doi.org/10.5172/mra.2010.4.2.090

[55] Ritchie, J. and Spencer, L. (1993) Qualitative Data Analysis for Applied Policy Research. In: Bryman, A. and Burgess, R., Eds., Analysing Qualitative Data, Routledge, London, 173-194.

[56] Pope, C., Ziebland, S. and Mays, N. (2000) Qualitative Research in Health Care. BMJ, 320, 114-116. http://dx.doi.org/10.1136/bmj.320.7227.114

[57] Sharp, K. (1998) The Case for Case Studies in Nursing Research: The Problem of Generalization. Journal of Advanced Nursing, 27, 785-789. http://dx.doi.org/10.1046/j.1365-2648.1998.00604.x. 